\title{
The Teaching Mode of College Computer Foundation Flipped Classroom Based on the "Case-Task"
}

\author{
Qi Wenbin
}

Qingdao Huanghai College

Keywords: College Computer Foundation; flipped classroom; case teaching

\begin{abstract}
Starting from the characteristics of the course "College Computer Foundation", this paper analyzes the present situation and existing problems of the course teaching, and puts forward the implementation strategy of "College Computer Foundation" flipped classroom teaching mode based on "case-task".
\end{abstract}

\section{The Current Teaching Situation of "College Computer Foundation"}

"College computer foundation" is the main course in computer general course, which is a compulsory course for non-computer major undergraduates in colleges and universities of our country. In recent years, with the concept of "computing big data" being put forward, this course is regarded by many experts and scholars as the basic course which is as important as university mathematics and university physics. In order to improve the teaching content of the course, we should weaken the office software and the common multimedia software explain in class, strengthen the explanation of computer system and working principle, and keep the original computer network and database content, add cloud computing, Internet of things, embedded systems and other cutting-edge technology introduction, greatly enhance the content of the curriculum.

With the increase of the depth and breadth of the curriculum content and the continuous compression of the school hours, a series of problems have emerged, which mainly show that most teachers still instil abstract theories and principles into the students, with simple examples, far away from the practical application; Due to the limitation of school hours, teachers do not have enough time to fully explain the important theories and concepts in the classroom, which often touch lightly, resulting in the students' smatter, the lack of effective classroom learning activities, and the lack of communication between teachers and students and between students and students. The classroom atmosphere is dull and students' lack of enthusiasm; the contradiction between the differences of students' ability to accept knowledge and the characteristics of "synchronous learning" in the traditional classroom makes the students' needs of individualized development unable to be satisfied.How can we solve these problems?

The appearance of the "flipping classroom" teaching mode has brought a new opportunity to the curriculum. Many domestic scholars have studied and explored it, but most of them remain at the theoretical level, and there are few effective teaching practices, although some colleges and universities have carried out practical research on the "flipping classroom" teaching model for the course "college computer foundation", there are still some problems: the curriculum knowledge is fragmented by learning resources such as micro-video before class. How to reconstruct the curriculum knowledge system? How to supervise students' pre-class study effectively? How to organize learning activities in class? To sum up, on the basis of fully studying the teaching mode of "flipping classroom" and "case teaching method", this paper puts forward a case-based flipping classroom teaching mode, and explores the effective ways to solve the problems in the course of "college computer foundation".

\section{The Implementation Strategy of Flipped Classroom Teaching Mode Based on Case-task}

In the course "college computer foundation", a case-based flipping classroom teaching model is 
implemented. It mainly consists of nine steps: case design, production of pre-school learning resources, production and distribution of task list, pre-class discussion and feedback on the report list, design of classroom learning activities, organization of classroom learning activities, after-class development cases, after-class communication, evaluation and improvement.

Case is the basis of developing case-based flipping classroom teaching model. The selection and design of cases directly affect the learning effect of students. Teachers should select and design cases according to the teaching objectives and contents of the course, considering the characteristics of students and combining with the characteristics of the specialty of the school. According to the characteristics of the major of our school, we design special cases, such as "modern information technology", and select "logistics short distance distribution system" as the case, which is close to the students' major, and also has integrity, typicality and inspiration.

The teacher combs the knowledge points around the case, completes the fragmentation processing of the knowledge, prepares the learning resources such as the subsequent production of micro-video, and analyzes the inheritance relationship between the knowledge points before and after with the help of the software such as the thinking map, think about the form of each knowledge point (such as micro-video, animation, audio, text materials, etc.), design and make the learning resource package based on micro-video. For example, in the case of "logistics short distance distribution system", there are two knowledge points: general information processing process, main information technology, design and make one logistics short distance distribution system flash animation, two main information technology brief introduction micro video, one text data respectively.

In order to help and guide students to effectively complete pre-class learning resources, teachers need to make pre-class learning task list. According to the logical relationship of the knowledge points, the task list arranges the order of the learning tasks before class, and points out the corresponding learning resources, learning goals and thinking problems of each task. Among them, thinking problem should be the focused, difficult and doubtful problem in the case, which is enlightening, can arouse the collision of students' views and lead to heated discussion. For example, the author around the "logistics short distance distribution system" case, "Can modern information technology solve all the problems in your field of major? Why? Give an example. "and so on are raised in the task list. These questions can not only stimulate the students' strong interest in learning, but also need students to collect and organize the data carefully, and use critical thinking to find out the answers. Pre-class task list can be distributed with the help of network platform, such as QQ software, Lan Mo Yun class mobile phone APP.

In order to urge students to finish their tasks before class on time and to give timely feedback to teachers, in the course of "college computer foundation", the author asks students to take groups as units, discuss the thinking problems in the task list before class and feedback the report list before class. The group size is generally controlled at 6-7 students, the students are in free association, the group leader takes turns, and the main duties of the group leader are to organize the group members to conduct discussions before class, to evaluate each other's learning effects, to write and feedback reports, and so on. The report list should record the whole discussion process, existing problems, mutual evaluation results, etc. After the teacher received the feedback report list, according to the discussion of each group, the teacher evaluation results of each group were given. In order to verify the effectiveness of mutual assessment in the group, teachers can randomly select group members to answer questions in class. If the answers are not consistent with the results of the mutual evaluation, the "continuous sitting system" is adopted to reduce the group teachers' evaluation results. This strategy can effectively urge students to finish their pre-class study according to the task list, avoid "playing soy sauce" students, and strengthen the spirit of teamwork. At the same time, the pre-class study report card also provides effective feedback for teachers to design classroom learning activities.

According to the feedback of the pre-class report list, the teacher determines the focused, difficult and doubtful problem, and designs the classroom learning activities. The form of activity should be designed according to the type, characteristics and purpose of the case, for example, for 
the case of "logistics short distance distribution system", the classroom can be discussed, reported and so on;The case of "Harry's magic" designed by the author on the principle of binary to decimal conversion is suitable for the form of game. Activity design in the consideration of education in fun, naturally integrates knowledge and creates a classroom atmosphere of teacher-student and student-student interaction, which greatly stimulates students' enthusiasm for learning. Teachers should carefully plan the classroom time, design the appropriate number of cases, and provide students with a variety of learning channels and methods.

The whole classroom organization is student-centered. For example, in the case discussion activity, the teacher starts with the case background analysis, brings the student into the real application situation, throws out the question, organizes the student to discuss in groups. The teacher guides the group discussion direction, completes one to one or one to many tutoring, pays attention to control the discussion time, after the discussion completes, the group carries on the report and the defense, finally the teacher summarizes and evaluates.

After-class development cases need to be based on pre-class and class cases to further expand to the depth of the direction. For example, in the part of "modern information technology", the author takes "the design of apple picking robot system" as the development case. First of all, let the students adopt the same method as the classroom case analysis to analyze the main information technology involved in the case, further analysis of each technology mainly solved the problem, what is the solution to the problem, and finally draw the system function sketch and annotate. Through this practice, the students have a better understanding of the role, status and application of modern information technology, and improve their ability to solve problems.

With the help of online and offline face-to-face communication, teachers listen to students' feelings about the case-based flipping classroom teaching model, understand whether the pre-class learning task list setting is reasonable or not, and the students' suggestions on classroom learning activities. It plays an important role in the implementation of the follow-up teaching model and the improvement of students' learning quality. In the process of implementation, the author has received feedback from many students, they generally think that this teaching model greatly stimulates learning interest, has a strong sense of participation, and has greatly improved the ability of autonomous learning. The integration of real cases enables them to truly understand the mapping relationship between "computational thinking" and solving practical problems, and the knowledge learned is more complete and systematic.

After the implementation of the first case-based flipping classroom teaching model, teachers comprehensively evaluate the effectiveness of the teaching model through questionnaires, examinations, face-to-face communication and so on. In the course of "college computer foundation", the author makes a comparative evaluation of the two classes with him by means of questionnaire, final examination and ordinary test. One of the classes is the experimental class, which adopts the case-based flipping classroom teaching model. The other class is the traditional class, which adopts the traditional teaching model. The results showed that the average test score of the experimental class was 8.5 points higher than that of the traditional class, and the students' satisfaction was higher. In view of the shortcomings in the reform process, from the case design, design of pre-class task list,organization of classroom learning activities and other aspects of appropriate adjustment, modify and improve the implementation of the teaching model strategy, for the next round of application preparation.

\section{Reflection}

Case base construction is the foundation to guarantee the smooth implementation of case-based flipping classroom teaching model. In addition to the characteristics of integrity, authenticity, enlightenment and interest, cases should be collected and arranged in combination with the characteristics of the school specialty, so as to form a case base with special characteristics of the school, and be closer to the students' major, let students understand the application of modern information technology in the professional field, and prepare for the follow-up personal professional development. 
Case-based flipping classroom teaching mode requires teachers to invest a lot of energy and time before class to complete the curriculum planning, design cases, curriculum resources, task list, classroom activities and so on. This puts forward higher requirements for teachers, they must have solid professional knowledge, have great teaching enthusiasm, have a strong classroom organization skills and good communication skills.

Diversified evaluation system can effectively promote the implementation of case-based flipping classroom teaching model.How to urge students to complete their tasks before class? How to stimulate students to think actively and participate in discussion in class? To solve these problems, we need to rely on reasonable and effective multiple evaluation methods, and teachers need to set up an evaluation system that matches the teaching model according to the characteristics of students and courses.

This paper introduces the case teaching method into the flipping classroom teaching mode, and carries on the practical exploration in the course of "college computer foundation", which drives the flipping classroom teaching with the real application case. Discussing the case design, production of pre-class learning resources, production and distribution of task list, pre-class discussion and feedback on the report list and other aspects, the paper points out the key points of the implementation of the case-based flipping classroom teaching model.

\section{References}

[1] Chen Guoliang, Dong Rongsheng. Computational thinking and basic computer education in universities [J] .Chinese University Teaching, 2011, (1).

[2] Lan Chunxia. An empirical study on the teaching of computer basic course in higher vocational colleges based on flipping classroom [J] .Vocational Education Forum, 2015, (23).

[3] Jin Yan. A practical study on the mode of flipping classroom teaching based on micro-class--taking the course of "computer application foundation" as an example [J] .Vocational Education Forum, 2014, (23).

[4] Wei Linjing, Chen Lei. The course and case teaching method of "college computer foundation" [J]. Journal of Changchun Normal University, 2016,(2). 